

\title{
Quiet Short-Haul Research Aircraft Joint Navy/NASA Sea Trials
}

\author{
NASATM- - 8/ - \\ 208077 \\ S. Queen* \\ Test Center, Patuxent River, $M d$. \\ and \\ J. Cochranet \\ NASA Ames Research Center, Moffett Field, Calif.
}

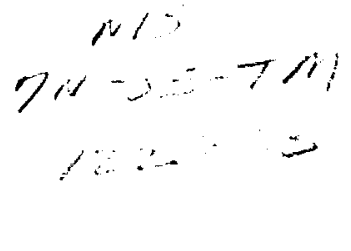

\begin{abstract}
The Quiet Short-Haul Research Aircraft (QSRA) is a flight facility which Ames Research Center is using to conduct a broad program of terminal area and low-speed, propulsive-lift flight research. A joint $\mathrm{Navy} / \mathrm{NASA}$ flight research program used the QSRA to investigate the application of advanced propulsive-lift technology to the naval aircraft-carrier environment. Flight performance of the QSRA is presented together with the results of the joint Navy/NASA flight program. During the joint program, the QSRA operated aboard the USS Kitty Hawk for 4 dass, during which numerous unarrested landings and free deck takeoffs were accomplished. These operations demonstrated that a large aircraft incorporating upper-surface-blowing, propulsive-lift lechnology can be operated in the aircraft-carrier environment without any unusual problems.
\end{abstract}

\section{Introduction}

$\mathbf{T}$ HE Quiet Short-Haul Research Aircraft (QSRA) is an advanced propulsive-lift research aircraft that NASA is using in a broad long-range flight research program. The QSRA is strictly a research aircraft - it is not a prototype of any projected operational aircraft. Its mission is to generate data for use by the United States aerospace industry and various government agencies in the specification, design, and certification of future propulsive-lift aircraft and their related systems.

The QSRA has high levels of STOL performance, and its simple but versatile systems permit a wide variety of flight investigations. The STOL performance capabilities of the QSRA led the U.S. Navy to consider it for use in an investigation of operating large propulsive-lift STOL aircraft from aircraft carriers.

\section{Description of the Airplane}

The Quiet Short-Haul Research Aircraft project was initiated at Ames Research Center in January 1974. Following the completion of preliminary design studies and a design competition, the Boeing Commercial Airplane Company was awarded a contract in February 1976 to modify a de Havilland C-8 Buffalo aircraft into the QSRA configuration. The modification consisted of a new, moderately swept wing and four Lycoming YF-102 engines, installed so as to provide an upper-surface-blowing, propulsive-lift system. The fuselage and empennage of the $\mathrm{C}-8$ were used with only minor structural modifications. Since its delivery to Ames Research Center in August 1978, the QSRA has been engaged in an intensive flight research program.

The general configuration and dimensional data of the QSRA are shown in Fig. 1; Fig. 2 shows the airplane in the landing configuration. Principal operational data are provided in Table 1.

\section{Airplane Flight Performance}

The QSRA achieves a high level of STOL performance by employing an upper-surface-blowing (USB), propulsive-lift

Presented as Paper 81-0152 at the AlAA 19th Aerospace Sciences Meeting, St. Louis, Mo., Jan. 12-15, 1981; submitted March 3, 1981 ; revision received Oct. 29,1981 . This paper is declared a work of the U. Government and therefore is in the public domain.

- Commander, USN

+Manager, Quict Shor1-Haul Aircraft Office. Member AlAA. concept. Lift is the summation of the basic wing aerodynamics, the thrust vector that results from flow turning, and the aerodynamic supercirculation created by the pumping action of the high-energy engine-nozzle flow over the wing's upper surface.

Figure 3 presents the QSRA lift-coefficient characteristics related to the takeoff ( 0 or $10 \mathrm{deg}$ USB) and go-around ( $30 \mathrm{deg}$ USB) configurations. All engines are operating (AEO) at $89 \%$ fan rpm (maximum thrust). To enhance the spanwise wing loading, the outboard double-slotted flaps are deflected 59 deg (which concurrently droops the ailerons $22 \mathrm{deg}$ ). The data shown in Fig. 3 are from night tests; they incorporate corrections for position error and center-of-gravity accelerations.

With the USB flaps retracted $(0 \mathrm{deg})$, approximately $18 \mathrm{deg}$ of flow-turning exists because of contouring of the upper surface of the wing and 4.5-deg wing incidence; this accounts for the lift coefficient exceeding 4.0. By extending the USB flaps $10 \mathrm{deg}$, the ground roll is shortened due to the reduced rotation requirement ( $50 \%$ less alpha to achicve a given lift). Further USB flap deffection for takeoff tends to increase the ground roll due to a reduction of horizontal thrust vector and, thus, the longitudinal acceleration. Thirty degrees USB is used for go-around to maximize the powered-lift $L / D$ ratio.

Figure 4 presents the QSRA lift coefficient characteristics related to the normal landing approach configuration (50-deg USB). The effects of engine power sellings, expressed as constant fan percent revolutions per minute, are included. Flight idle is $55 \%$ fan $\mathrm{rpm}$, and maximum thrust $(10-\mathrm{min}$ limit) is $89 \%$ fan rpm. Normal landing approaches are made using $70-80 \%$ fan rpm. USB flap deflections greater than 50 deg cause a reduction of the trimmed lift coefficient because of the associated larger nose-down pitching moments which, in turn, require more horizontal tail-down load to balance.

Normal landing approaches are conducted at $65-70$ knots. If a go-around is required, nearly level flight can be achieved without reducing the USB flap deflection or increasing speed. USB flap deflections greater than 30 deg are set by the use of a throttle-lever-mounted switch. Thus the pilot uses the same hand that increases power for the go-around to simultaneously retract the USB flaps to the go-around setting; this guarantees a positive climb rate (the USB flaps move at $7 \mathrm{deg} / \mathrm{s}$ in the 30-66-deg deflection range).

An important consideration in all multiengine aircraft is engine-out performance. This factor is particularly important in the operation of propulsive-lift aircraft. Unfortunately, during preliminary design studies, preoccupation with allengine-operating performance sometimes causes this factor to 


\begin{tabular}{|c|c|c|c|}
\hline \multicolumn{4}{|c|}{ AERODYNAMIC DATA } \\
\hline & WING & HORIZ & VERT \\
\hline AAEA (TRAP), $h^{2}$ & 6000 & 233.0 & 152.0 \\
\hline SPAN & 73.5 & 320 & 14.0 \\
\hline ASPECT AATIO & 9.0 & 44 & 1.22 \\
\hline TAPER RATIO & 0.30 & 0.75 & 0.60 \\
\hline SWIEEP C/4, deg & 15.0 & 30 & 180 \\
\hline M.A.C. in. & 107.4 & 880 & 137.0 \\
\hline CHORO ROOT, in. & 150.7 & 100.0 & 1680 \\
\hline CHORD TIP, in. & 45.2 & 75.0 & 100.0 \\
\hline T/C BODY SIDE, $*$ & 18.54 & 14 & 14 \\
\hline$T / C T I P, \times$ & 15.12 & 12 & 14 \\
\hline INCIDENCE, deg & 1.5 & - & - \\
\hline DIHEORAL, deg & 0.0 & - & - \\
\hline TAIL ARM, in. & - & $525.0 \mathrm{~m}$. & $488.0 \mathrm{~m}$. \\
\hline VOL COEfF & - & 1.898 & 0.1402 \\
\hline
\end{tabular}

CONTROL SURFACES
\begin{tabular}{|l|l|l|}
\hline \multicolumn{2}{|c|}{$\mathrm{H}^{2}$ IAPL } & BLOWN \\
\hline AILERON & 32.2 & BLC \\
\hline FLAPS INBD & $79.0^{\circ}$ & USB \\
\hline FLAPS OUTBD & $39.6^{\circ}$ & NONE \\
\hline SPOILERS & 32.8 & NONE \\
\hline L.E. FLAPS & 51.6 & NONE \\
\hline ELEVATOA & 81.6 & NONE \\
\hline RUDDER & 60.8 & NONE \\
\hline
\end{tabular}

- THEORE TICAL RETHACED aREa

LANDING GEAR
\begin{tabular}{|c|c|c|c|c|}
\hline GEAR & STROKE & TIAE & TIRE O.D & ROLLING RAD \\
\hline MLG. in. & 21.0 & $11.5-15$ NEW DESIGN & 32.0 & 13.5 \\
\hline NLG, in. & 17.5 & $8.90 \cdot 12.50$ TYPE III & 27.5 & 12.0 \\
\hline
\end{tabular}
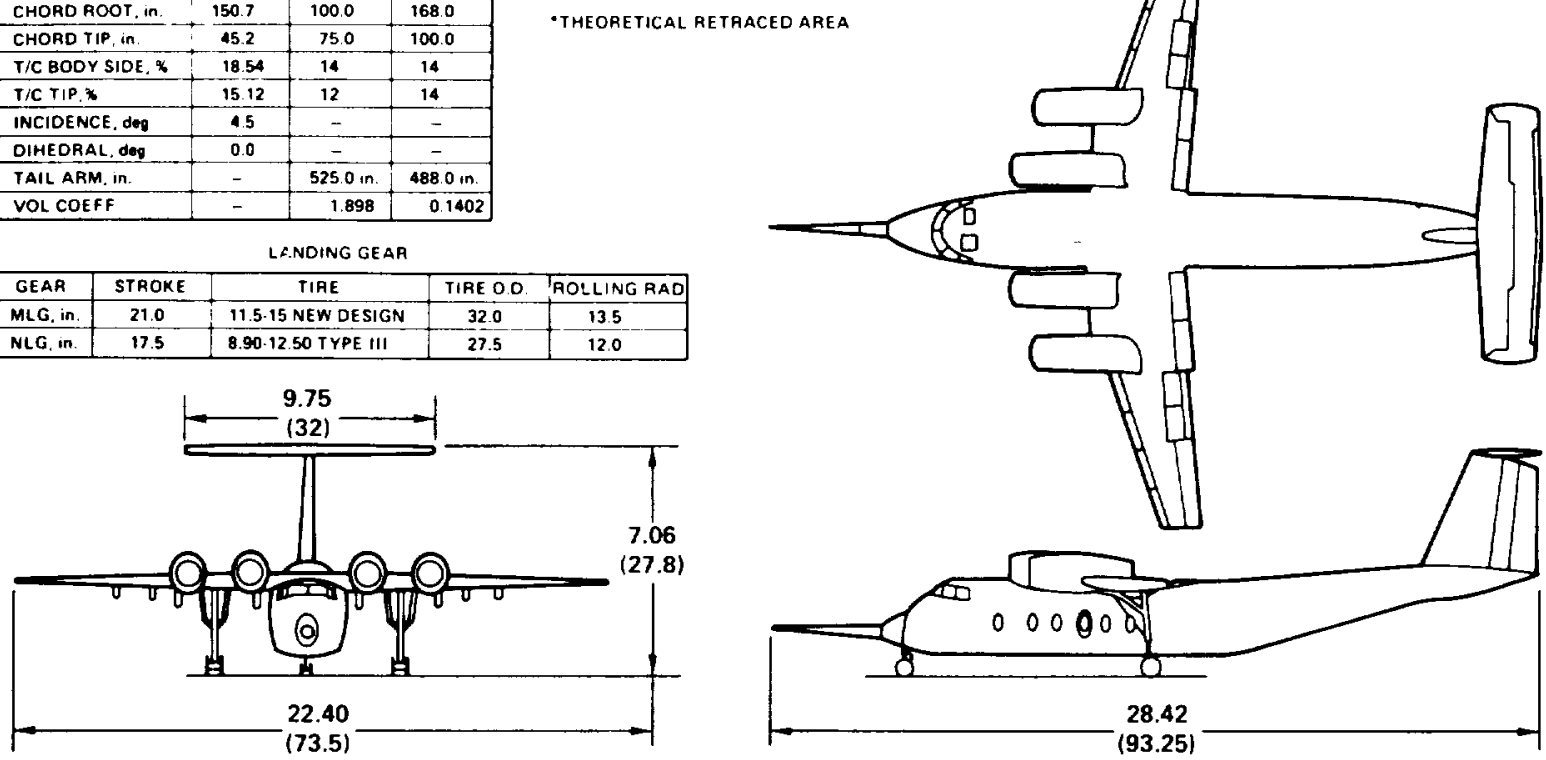

Fig. 1 QSRA design and configuration data.

Table 1 QSRA characteristics

\begin{tabular}{ll}
\hline \hline Design takeoff gross weight & $50,000 \mathrm{lb}$ \\
Maximum takeoff gross weight & $60,000 \mathrm{lb}$ \\
Demonstrated maximum takeoff gross weight & $57,000 \mathrm{lb}$ \\
Wing loading at design gross weight & $83 \mathrm{psf}$ \\
Thrust-to-weight at design gross weight & 0.50 \\
& $($ measured) \\
Maximum sink rate at design gross weight & $12 \mathrm{ft} / \mathrm{s}$ \\
Wing fuel capacity & $10,670 \mathrm{lb}$ \\
Fuselage fuel capacity & $5409 \mathrm{lb}$ \\
Range with 45-min reserve $(2800 \mathrm{lb})$ & $387 \mathrm{n} . \mathrm{mi}$. \\
Typical test mission duration & $21 / 4 \mathrm{~h}$ \\
Long-range cruise speed at $10,000 \mathrm{ft}$ & $170 \mathrm{KIAS}$ \\
Design ceiling & $15,000 \mathrm{ft}$ \\
\hline \hline
\end{tabular}

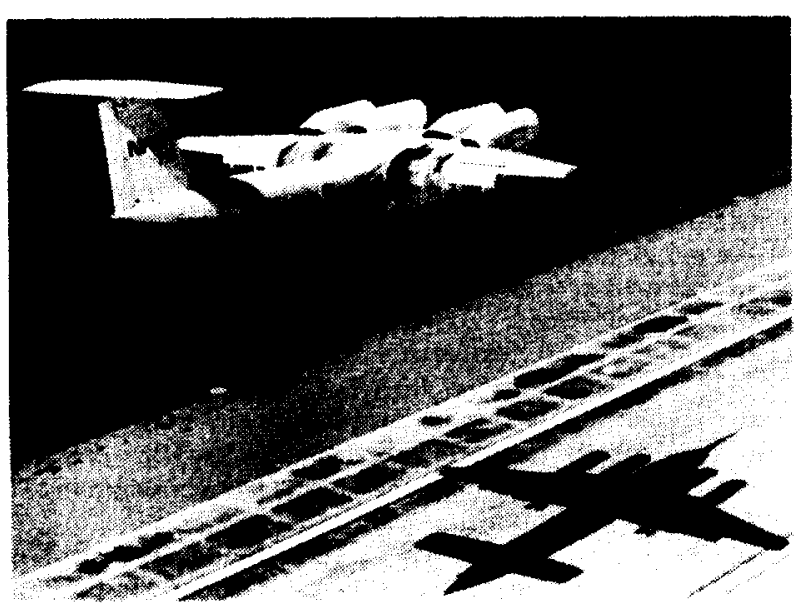

Fig. 2 QSRA flying over simulated carrier deck. be neglected. Figure 5 shows the measured takeoff performance of the QSRA with either an outboard or an inboard engine inoperative at the start of the takeoff roll (a 3-engine takeoff). Throttle chops at various points in the takeoff roll were also evaluated. These conditions (throttle chop instead of 3-engine takeoff) reduced the takeoff roll and did not introduce any unusual control problems.

Figure 6 shows the landing approach performance of the QSRA with an inboard or an outboard engine at ground idle with the USB flaps at $55 \mathrm{deg}$. Note that the loss of an inboard engine results in a greater lift loss and steeper night path than the loss of an outboard engine. However, a greater wheel deflection is required to laterally trim the loss of an outboard engine than that required for the loss of an inboard engine.

Thus the loss of an inboard engine is critical from a performance point of view, while loss of an outboard engine is critical from control considerations. Engine-out control and performance factors for takeoff, approach, and landing must be considered in the evaluation of propulsive-lift STOL airplane performance. Thus, because of engine-out takeoff performance and the aircraft-carrier angle deck length available, free deck takeoffs by the QSRA from the USS Kitty Hawk were limited to a minimum wind over deck of 20 knots.

\section{QSRA Aircraft-Carrier Flight Research Program}

Planners in the Naval Air Systems Command are faced with tough future ship procurement decisions. An experimental approach was taken for answering the following questions:

1) With the requirement to replace an aging fleet by the year 2000 , what type ships should be purchased? Present CV carriers? Different type carriers with radical launch/approach/airwing concepts?

2) Can new technology provide short takeoff/landing capability? If so, how is this hardware implemented and how does it affect aircraft-ship interface? 


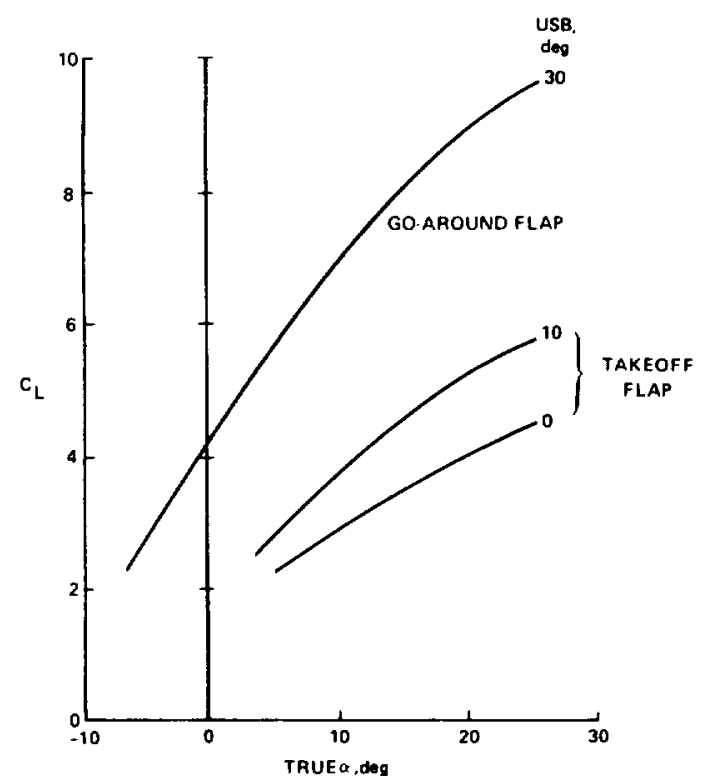

Fig. 3 Corrected lift coefficients: all engines operating at $89 \% \mathrm{rpm}$, double-slotted flaps deflected $59 \mathrm{deg}$.

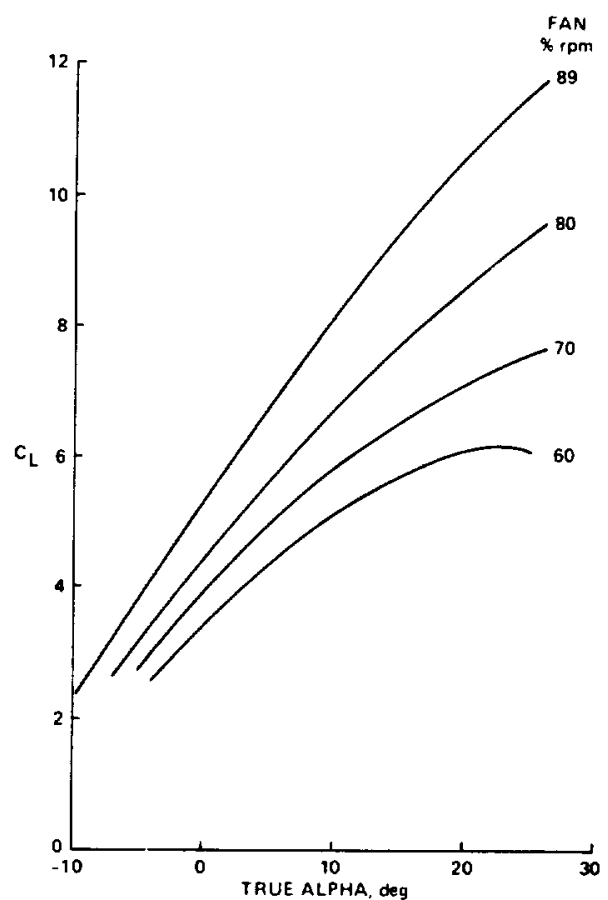

Fig. 4 Corrected lift coefficients: all engines operating, doubleslotted flaps deflected $59 \mathrm{deg}$, and USB $=50 \mathrm{deg}$.

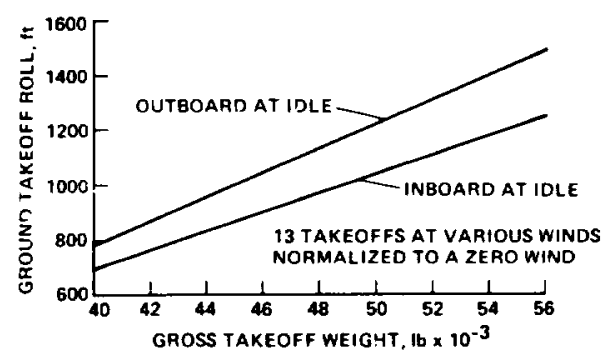

Fig. 5 QSRA takeoff performance: $U S B=10 \mathrm{deg}$, critical engine inoperative.

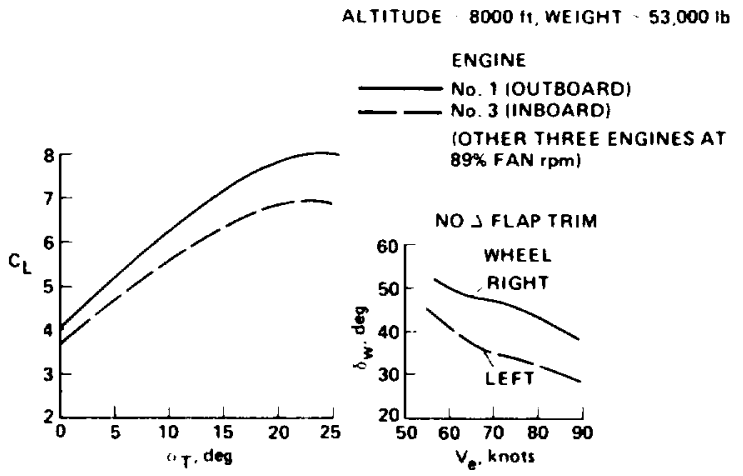

Fig. 6 Engine-out characteristics: double-slotted flaps deflected 59 deg, USB = 55 deg.

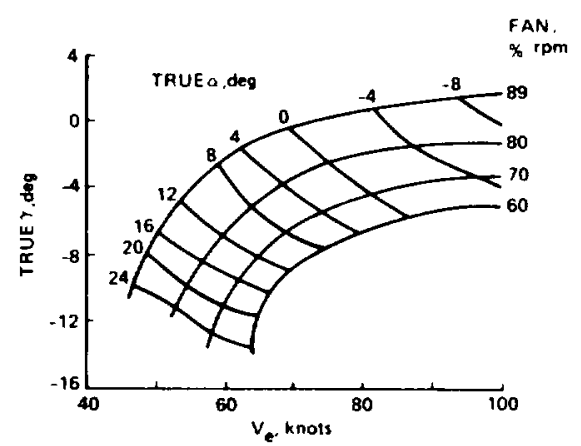

Fig. 7 Flight-path and angle-of-attack characteristics: all engines operaling, double-slotted flaps deflected $59 \mathrm{deg}$, USB $=50 \mathrm{deg}$.

3) How does one probe and evaluate the unknowns of these experimental ideas?

4) What is the real payoff to these concepts?

These questions have to be answered before procurement decisions are made. The program undertaken to answer them is a many-faceted one and only one phase of many in which the Navy is presently involved. Specifically the Navy is interested in propulsive-lift technology and its applications and difficulties as they relate to a carrier environment.

The Navy opened preliminary discussions with Ames Research Center concerning the use of the QSRA for sea trials as well as for investigating other potential STOL-STOAL capabilities in November 1979. By March of 1980 the Naval Air Test Center test team was on site at NAS Moffett Field for preliminary evaluation of the capabilities and methods to be used to take the QSRA to sea aboard a Navy aircraft carrier. The evaluation comprised two phases: shore-based tests (phase I) and sea trials (phase II). Overall objectives for both phases were to

1) determine the best technique for landing STOL aircraft on carriers;

2) determine the effects of ship aerodynamic wake, ground effect, and ship's motion on unarrested carrier landings;

3) evaluate the operation of large STOL propulsive-lift aircraft in the shipboard environment; and

4) obtain design data and operational criteria for future Navy use.

\section{Phase I: Shore-Based Tests}

Phase I began March 31, 1980, with the arrival of the Navy test team at Ames Research Center. The Navy team consisted of two pilots, a landing-signal officer (LSO), and two flighttest engineers. A flight-deck officer with three support crewmen were on site part time. The first 2 weeks were spent in ground school and on checkout flights. The remainder of the shore-based testing was dedicated to selecting approach 


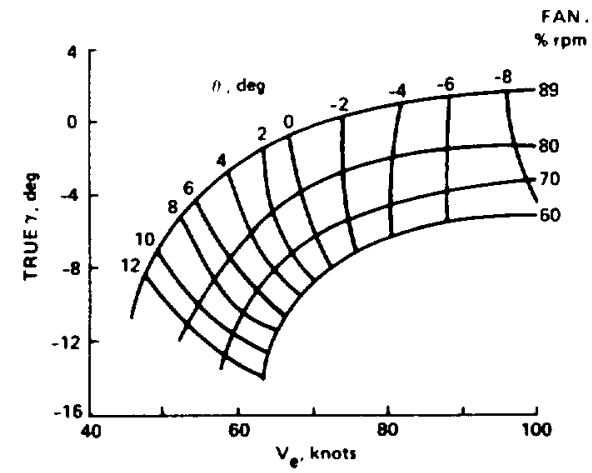

Fig. 8 Flight-path and pitch allitude characteristics: all engines operating, double-slotted flaps deflected $59 \mathrm{deg}, \mathrm{USB}=50 \mathrm{deg}$.

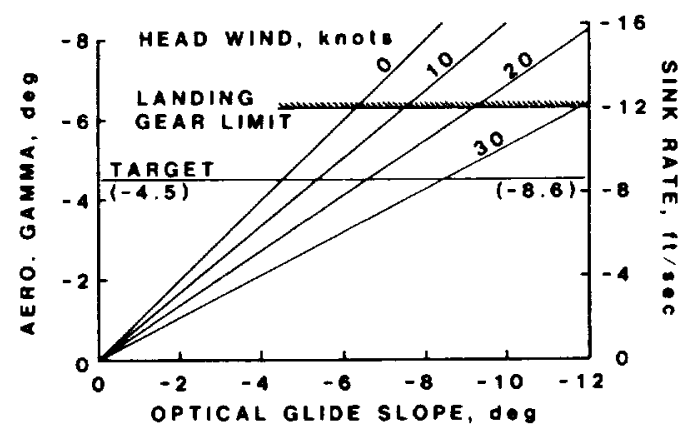

Fig. 9 65-knot approach planning chart.

parameters and obtaining statistical data for touchdown/sink-rate dispersion.

Figure 7 presents the flight-path and angle-of-attack characteristics as functions of airspeed for the airplane in the approach configuration at various power settings. Attempts to fly a constant angle of attack during the approach as is normally done with current carrier aircraft provided a marginal ability 10 change the flight-path angle while producing excessive airspeed excursions. Figure 8 presents the same airspeed and flight-path characteristics with lines of constant pitch attitude. Flying a relatively constant-pitch attitude $(+110+3 \mathrm{deg})$ during the approach produced a relatively constant airspeed (5-7-knot variation in approach speed) over a reasonably large range of flight-path angles. Angle of attack varied between 7 and $12 \mathrm{deg}$, but provided ample stall margins. Therefore the decision was made to fly the approach at constant pitch attitude and flap setting, allowing airspeed to vary as a function of gross weight between 65.70 KIAS. This technique was made easier for the pilot by the rate-command, attitude-hold pitch augmentation system.

During previous NASA tests and early in this program, the QSRA was observed to be susceptible to floating in ground effect during shallow approaches (less than 3-deg flight-path angle). As a result, it was decided to fly the carrier approach as steeply as possible without exceeding the aircraft's $12-\mathrm{ft} / \mathrm{s}$ sink-rate limit. Steeper approaches would also provide improved touchdown dispersion (a great help for unarrested landings aboard ship) and maximize wheel-to-ramp clearance for safety. A 4.5-deg aerodynamic flight-path angle was finally selected when it was determined that it produced an acceptable sink rate $(8.6 \mathrm{ft} / \mathrm{s})$ and provided ample margin while overcoming the floating tendencies in ground effect (see Fig. 9). To keep this value constant during all wind conditions, the Fresnel lens oprical landing system (FLOLS) used for these tests was adjusted as indicated by Fig. 9. Note that conventional carrier-based aircraft such as the F-14 have a
Table 2 Phase I malfunction cases investigated

Engine out:

Inboard and outboard

Cruise, climb, approach, wave-off, and takeofi

SAS failures:

Pitch, roll, and yaw inoperative

DLC failure

Conclusion: failures easily handled by normal operational procedures

design sink rate of $22 \mathrm{ft} / \mathrm{s}$ with a target touchdown sink rate of $12-13 \mathrm{ft} / \mathrm{s}$. Attempts to flare during landing destroyed the precision desired for touchdown during these tests and was ruled out as an approach technique. An approach attitude, $\theta$, of +1 to +3 deg was selected because of the criterion previously mentioned and also because it allowed the aircraft to touch down without flaring. Because of wind shear and gusts, slight adjustments of pitch attitude were required to correct airspeed during the approach.

Flap settings were varied during the initial configuration evaluation. It was determined that, except for gross airspeed deviations necessitating flap movement to change aircraft drag, all approaches would be conducted using a constant flap setting (50-deg USB). This was because excessive attitude and power changes were required with changes in flap setting during the approach.

Airspeed control was of great concern during this evaluation since the pilot was given no wheel force feedback as speed changed. The airspeed indicator was not in an optimal position for carrier approach-scan pattern and compounded the pilot's airspeed-control problem. A speed-hold system was installed in the test vehicle, but insufficient development time precluded its use during sea trials. Since speed-hold could not be used, a speed indexer was installed and placed in the approach-scan pattern to allow the pilot to monitor airspeed trends. The indexer was standard Navy issue except that airspeed rather than angle of attack was used as the control function. This installation proved quite valuable during the sea trials.

Approaches were flown with pitch SAS off, mainly to familiarize the Navy pilots with the characteristics of the unaugmented airplane. Although the aircraft was manageable with the pitch SAS off, the pilot's workload was increased, and the aircraft lacked the precision tracking required to operate in the shipboard environment. For this reason the decision was made to require a fully functional pitch SAS for actual sea trials.

The direct-lift-control (DLC) system provided more than adequate flight-path control authority (heave response) with minimal power (rpm) changes. With the DLC off, the flightpath control was severely degraded and the pilot tended to get into a divergent flight-path oscillation close to touchdown (because the power was in a low-thrust range and power response did not coincide with pilot input). By deploying the spoilers to a nominal $-13 \mathrm{deg}$ (DL.C neutral bias position), higher power settings were used owing to increased drag and loss of lift. The higher power settings caused the engines to be in a more responsive range (greater than $80 \% \mathrm{rpm}$ ) and resulted in smoother flight-path control. Control in this configuration still was not as precise as with DLC on; however, it provided enough control authority and precision to be used aboard ship in the event of a DLC failure.

The malfunction cases investigated during phase $l$ included various engine-out conditions, SAS failures, and a DLC failure. Engine failures were simulated during the takeoff roll, climb, cruise, approach, and wave-off. The only area of concern following these tests was the possibility of an engine failure late in the approach while operating at high gross weight or at high ambient temperatures. The effects of an engine failure were readily apparent and pilot corrective action was instinctive. Nevertheless, under conditions of high 
gross weight and/or high ambient temperatures, immediate flap retraction was required to execute a successful wave-off. A summary of malfunction cases is given in Table 2 .

The takeoff configuration was evaluated qualitatively, based on handling qualities, as well as quantitatively, based on minimum ground run requirements. The tests were conducted by varying the USB flap setting between 0 and $30 \mathrm{deg}$ in 5-deg increments with the double-slotted flaps full down at 59 deg. Handling and flying qualities did not change significantly as USB flap setting was varied. Therefore the 10deg USB flap setting determination for takeof $f$ was based entirely on the quantitative numbers found for minimum ground run. The piloting technique utilized was full aft wheel throughout ground run until airplane rotation and liftoff.

Ground handling was evaluated in the presence of a naval flight-deck officer and Navy ground crew, and was determined to be satisfactory for shipboard operations. Maximumbraking stops, using the aircraft's proportional antiskid system, resulted in satisfactory performance; however, owing to the cyclic nature of the antiskid and the landing gear dynamics, damage to equipment shock mounts inside the aircraft and corresponding failures in associated gear were experienced. Maximum-braking stops were also accomplished over arresting gear cables with no appreciable adverse effects. It was decided, however, to remove all arresting cables from the deck during actual shipboard landings in the interest of safety.

Electromagnetic vulnerability (EMV) tests were also accomplished during this phase. Potential interference was discovered in the airplane's pitch SAS and antiskid brakes. Electronic filters were installed in these systems to correct the potential hazard.

Figure 10 presents the shore-based QSRA touchdown dispersion data obtained from over 200 landings, including 46 to a full stop. These landings were made by four pilots (two Navy and two NASA) during phase I. A portable Fresnel lens identical to the one used aboard ship was used to provide

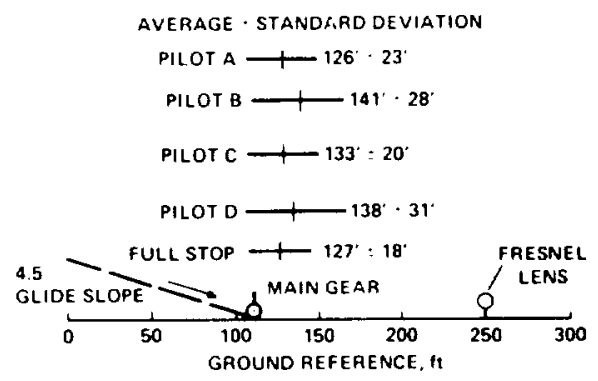

Fig. 10 Touchdown dispersion.

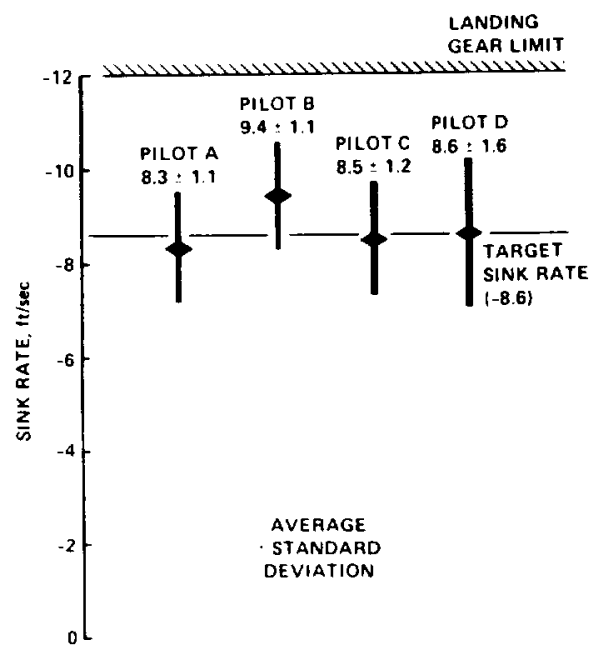

Fig. 11 Touchdown sink rates. glide-slope guidance. The relative locations of the Fresnel lens and the theoretical main-landing-gear touchdown point are also shown in Fig. 10. These data consist of the average touchdown points and the standard deviations, shown by the vertical lines and the horizontal bars, respectively. The data for each pilot include touch-and-go and full-stop landings. The category "full stop" includes all 46 full-stop landings by the four pi!ots. For the full-stop landings, it was felt that the pilot's gains were higher, resulting in an average closer to the theoretical louchdown point with less deviation from the average. The general tendency in all landings was to be on or above the glide slope. The average and standard deviation values demonstrate that a STOL aircraft can accurately achieve a given touchdown point. Considering that the approximate touchdown dispersion for current carrier aircraft during manually controlled approaches is approximately 60 $\mathrm{ft}$, the QSRA dispersion demonstrated significant improvement of present capabilities.

Figure 11 presents the sink rates measured during the landings described above. These data show that the average sink rate for each pilot was very close to the target rate of 8.6 $\mathrm{ft} / \mathrm{s}$ (see Fig. 9). There were no landings on which the limit of $12 \mathrm{ft} / \mathrm{s}$ was exceeded.

A presentation of takeoff and landing performance, relative to the flight deck of a Forrestal-class carrier, is shown in Fig. 12. Takeoff roll for the angle deck was initiated $\approx 100$ $f t$ forward of the round-down, and varied between the 200 and $400-\mathrm{ft}$ position for the straight deck. The standard deviation for the full-stop landings was added to a computed main-landing-gear touchdown point in order to arrive at a worse-case landing situation. Although it appears possible to do zero-wind takeoffs and full-stop landings, in the interest of safety and because of engine-out performance considerations, the operations here were restricted to a minimum of wind over the deck of 20 knots. A summary of phase I results is presented in Table 3.

\section{Phase II: Sea Trials}

Phase II sea trials were begun on July S, 1980, when the QSRA was ferried to NAS North Island. Following 3 days of field carrier landing practice (FCLP) under LSO supervision, the sea trials began on July 10, 1980, aboard the USS Kitty Hawk (CV 63), which was located approximately 100-n.mi. southwest of San Diego. During the 4 days of sea trials, 25 low approaches, 37 touch-and-go landings, and 16 full-stop landings were accomplished aboard ship. Crosswind takeoffs and landings and non-DLC approaches were also evaluated. In conjunction with these flight operations, engine-running refuelings and deck handling were demonstrated. Figure 13 pictures the QSRA aboard the Kitty Hawk, and Table 4 summarizes the operations aboard ship. Data taken aboard the Kitty Hawk will be presented in Refs. 1 and 2.

Standard Navy procedures were utilized where possible (i.e., Navy racetrack carrier pattern 600 -ft AGL) using the configurations determined most suitable during the shore phase. These consisted of 1) upwind: USB $=0 \mathrm{deg}, \mathrm{DSF}=59$ deg; 2) downwind: $U S B=30 \mathrm{deg}, \mathrm{DSF}=59 \mathrm{deg}, \mathrm{DLC}$ on; 3) 180-deg position: USB $=50 \mathrm{deg}(47 \mathrm{deg}$ for gross weights $>48,000 \mathrm{lb}$ ), DSF $=59 \mathrm{deg}$, DLC on.

Table 3 Phase I-key results

\begin{tabular}{l}
\hline Basic approach configuration determined to be \\
Aerodynamic glide slope $-4.5 \mathrm{deg}$ (adjust up for wind) \\
Pitch attitude +1 to $+3 \mathrm{deg}$ \\
Approach speed $65-70 \mathrm{knots}$ \\
USB flaps $50 \mathrm{deg}$ \\
Speed hold off \\
DLC on (but not essential) \\
Maximum landing gross weight $50,000 \mathrm{lb}$ \\
Fly Fresnel lens to deck-no flare \\
Takeoff configuration-USB flaps at $10 \mathrm{deg}$ \\
All performance compatible with ship \\
\hline \hline
\end{tabular}




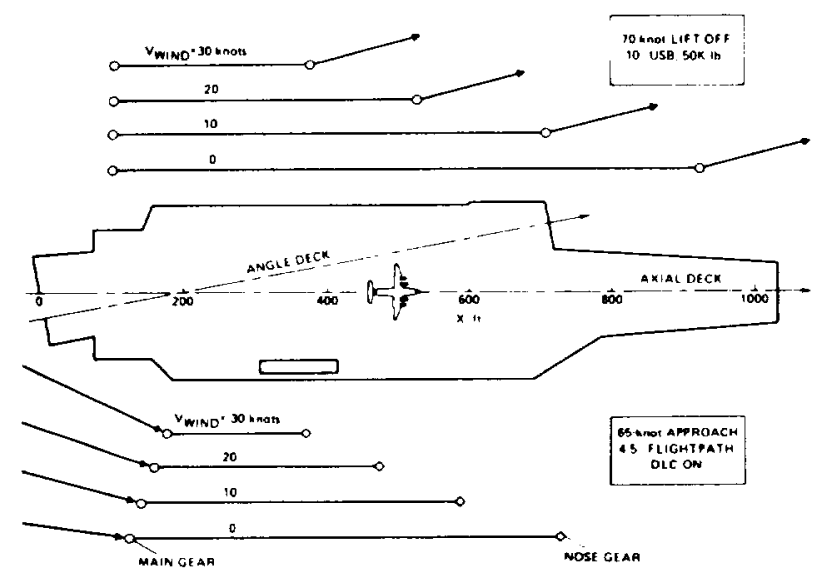

Fig. 12 Predicted carrier-deck reouirements.

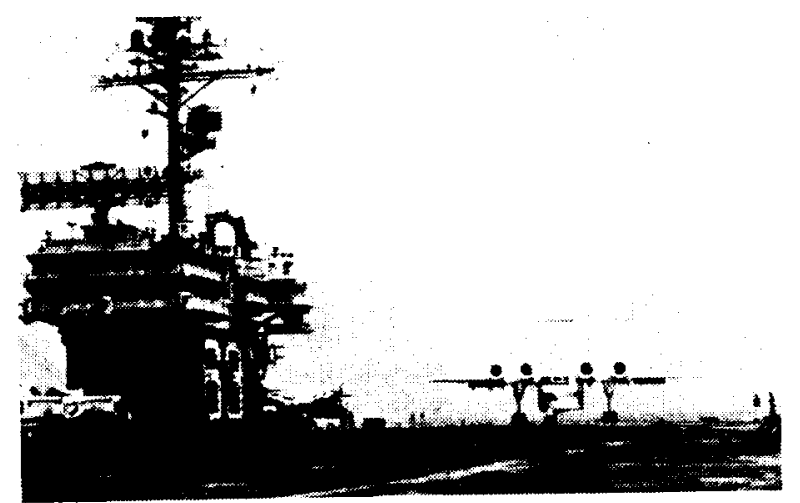

Fig. 13 QSRA aboard the USS Kitty Hawk.

Table 4 Summary of phase II sea Irials

Number of FCLP periods at North Island 9

At sea aboard USS Kitty Haw:k CV.63

Days of operation

Number of low approaches

Number of touch-and-go landings

Number of full-slop landings

Number of refueling stops at San Clemente

Crosswind takeoff and non-DLC approach evaluated

Hot refueling and deck handling demonst rated successfully

Lens acquisition was easily accomplished following the descending turn pattern, and glide-slope tracking was smooth and easily accomplished down to approximately $180 \mathrm{ft}$. At this point the ship's aerodynamic burble began to affect flight-path control causing the pilots to go slightly high. As in the case of conventional airplanes, the QSRA had an abrupt settling tendency as the round-down was crossed. Anticipation was required to control this settling in a smooth manner. This anticipation is consistent with present conventional airplane carrier operations. The steep approach angle, touchdown point, and airplane wheel-to-eye geometry precluded the use of the standard shipboard Fresnel lens optical landing system (FLOLS). A portable lens like the one used during shore-based tests was used. The portable lens was located about $250 \mathrm{ft}$ aft of the standard lens to satisfy touchdown geometry. This resulted in altitude-positiondiscrimination sensitivity as the airplane approached louchdown. This sensitivity was noted during the shore-based phase and was expected at sea. The angular proximity of the lens to the landing area also resulted in loss of glide-slope display information for the pilot shortly after crossing the round-down. Both glide-slope display anomalies were easily compensated for by all pilots during the tests, but were considered unacceptable for routine shipboard operations.

Lineup with the angle deck is the most demanding task during carrier operations; the QSRA proved to be no exception in this regard. All pilots initially landed left as the ship's motion affected their approach, but lateral displacement improved as experience was gained.

Deck handling proved to be better than expected. Tire wear on the abrasive nonskid covered carrier deck was less than expected and directional control during landing rollouts proved to be as easy as landing ashore had been.

All takeoffs were accomplished with USB flap at 10 deg and double-slotted flaps at $59 \mathrm{deg}$. Power was set at $80 \%$ fan speed prior to brake release. Maximum power was applied immediately after brake release. Full aft column was applied after the first indication of airspeed was observed. Using this technique the airplane rotated comfortably at 60 knots and lifted off at approximately $75 \mathrm{knots}$. The takeoff was smooth and precise using this technique. Some late-rotation takeoffs were accomplished; they resulted in crossing the end of the deck at a lower altitude. In two of these cases that also involved crosswind conditions, an abrupt lateral disturbance was encountered, which required full lateral control followed by several pilot-induced oscillations before damping out. No unusual disturbances were noted using the minimum takeoff roll technique, including crosswind takeoffs and landings.

The speed indexer was considered very valuable because constant attention to the lens was required for acceptable glide-path control. If at any time the pilot was forced to divert his attention from the lens, a significant glide-slope deviation could result.

\section{Conclusions and Recommendations}

The QSRA made repeated unarrested landings and free deck takeoffs from the USS Kitly Hawk while being flown by three pilots of significantly different backgrounds. The project demonstrated that USB propulsive-lift technology presents no unusual problems in the aircraft-carrier environment.

Optimum QSRA landing parameters determined during the shore-based program proved satisfactory during operations aboard ship. Correlation of shipboard experience with shorebased data indicates that both free deck takeoffs and unarrested landings could be conducted with winds across the deck of 0-35 knots from an aircraft carrier the size of the USS Kitty Hawk with all engines operating.

It was recommended that an improved optical flight-path guidance system be developed that would be less sensitive close in and located closer to the landing area centerline so as to ease the approach line-up task. It was also recommended that a smooth-acting antiskid brake system be developed to reduce structural stresses during maximum braking in order to improve equipment life.

\section{Acknowledgments}

The data presented in this paper were acquired and reduced during the joint Navy/NASA QSRA Flight Research Program by the staff of the Quiet Short-Haul Aircraft Office at NASA Ames Research Center. The authors wish especially to express their appreciation to Dennis Riddle and Victor Stevens, who originally prepared most of the charts presented herein.

\section{References}

'Stevens, V., Riddle, D., Martin, J., and Innis, R., "Powered-Lift STOL Aircraft Shipboard Flight Operations-A Comparison of Simulation, Land-Based, and Sea Trial Results for the QSRA," AlAA Paper 81-2480, Nov. 1981.

¿Queen, S.J., Strickland, P.B., Senn, C.P., and Webb, C.E., "Shipboard Trials of the NASA Quiet Short-Haul Research Aircraft (QSRA)," NATC Rept. SA-R-81, Oct. 1981. 